\title{
Constructing a physical model of the process of acoustic air pollution for brick manufacturing enterprises
}

\author{
Vadim Bespalov ${ }^{1}$, Oksana Gurova ${ }^{1}$, Valeriya Baklakova $^{2, *}$, and Natalya Samarskaya ${ }^{1}$ \\ ${ }^{1}$ Don State Technical University, 344022, 1, Gagarina sq., Rostov-on-Don, Russia \\ ${ }^{2}$ Institute of Service and Business (branch) Don State Technical University, 346500, 147, Shevchenko \\ st., Shakhty, Russia
}

\begin{abstract}
The article is devoted to the analysis of the physical nature of the air acoustic pollution process for the clay brick workshop of the brick factory molding department. According to the physical and energy approach, acoustic pollution of the air is considered as a multi-stage probabilistic process, the implementation of which depends on the physical characteristics of the objects involved in it at each stage and the characteristics of their interaction with each other. The physical model of the air acoustic pollution process constructed by the authors clearly reveals the physical essence of each stage of this process.
\end{abstract}

\section{Introduction}

Most of the technological processes in the construction industry are characterized by intense noise emissions. According to the analysis of statistical data over the past five years, $41 \%$ of the number of people employed in jobs with harmful and (or) dangerous working conditions in the construction industry are affected by such factors of the working environment as noise, air ultrasound and infrasound. The effect of noise on the human body is multifaceted and with regular exposure can cause a number of pathological changes. According to the research institute named after Erisman in various situations up to $10 \%$ of human health depends on the state of acoustic environment. Noise is a general biological irritant, since it affects not only the organ of hearing, but also the whole organism, and as a result reduces performing capacity and can lead to lower labor productivity and, consequently, to economic losses [1].

Despite the intensive development of modern methods of technological processes organization that can minimize the negative impact of production factors on workers in various fields of labor, the number of people employed in the construction industry has been increasing annually due to increased levels of noise and vibration and has increased by more than $9 \%$ since 2013 . The identified trend allows us to conclude that it is necessary to search for new protection systems against increased noise levels in the construction industry. The selection of means and methods of protection should be made taking into account the characteristics of the source of acoustic pollution and its physical parameters.

* Corresponding author: valeriya.baclackowa@yandex.ru 
Based on our analysis, we distinguished three groups of sources of noise pollution at enterprises in the construction industry, affecting both the health of workers and people living near enterprises. The first group includes equipment located in industrial buildings, the second comprises stationary noise sources on the territory of enterprises and the third includes mobile sources, which include vehicles involved in the work of construction industry enterprises [2].

Brick production can be distinguished as the most noisy, since almost all technological stages have elevated sound pressure levels. Having analyzed the technological equipment used in the manufacture of bricks, we came to the conclusion that it is the process of plastic molding of products that is accompanied by the release of noise up to 100-110 dBA. Thus, vacuum screw press SMK-506 was selected as the object of further research.

\section{Methods}

Research methods are based on the basic principles of systems modeling theory and probability theory, as well as scientific and analytical generalization of known practical and theoretical research results. The materials of the study are Russian and foreign scientific publications on the issue under study.

The object of research is the process of air acoustic pollution as a complex multi-stage process that takes into account behavior and basic physical characteristics of all objects taking part in it.

The most preferable method for studying the acoustic pollution process is physicalenergetic methodological approach, since it allows to identify the physical links that arise during the interaction of all the objects participating in this process and to predict their behavior under the influence of physical parameters [1, 3-5].

\section{Results}

In accordance with the chosen research approach we determined the main characteristics of the process of acoustic air pollution for the clay brick workshop of the molding department and we built a physical model of the process taking into account its main components: implementation stages and physical objects involved in each of them.

In the framework of the study we identified the main stages of air noise pollution during the successive implementation of which the generated sound waves propagate in the air of the working zone and in the surface layer of the atmosphere, as well as the main physical objects involved in the process at all stages are identified. When constructing the block diagram of the model, the main parameters and characteristics of all objects involved in the process of acoustic air pollution and determining the features of its pollution were taken into account (Figure 1). 




Fig. 1. Physical model of the process of acoustic air pollution. 
Thus, we consider the acoustic air pollution as a complex process consisting of several stages, at each of which various physical objects interact.

The first stage of the process of air pollution is formation of a sound wave that accompanies almost every technological process in which raw materials are used. The source of sound waves formation is often a part of technological equipment that implements the processing of raw materials. Let's schematically represent all the physical objects involved in the process of sound waves formation in figure 2 .

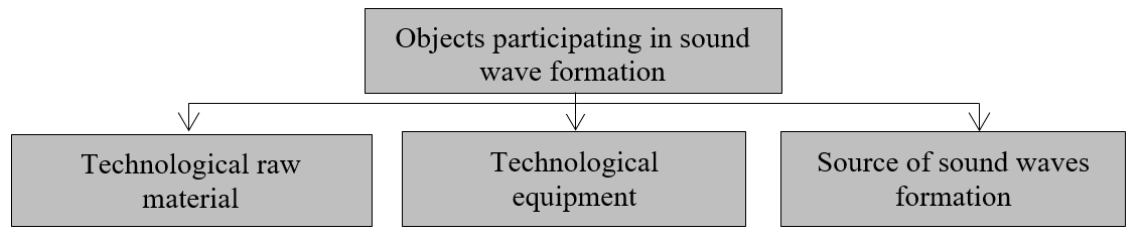

Fig. 2. Objects of the first stage of the acoustic air pollution process.

Technological raw materials take both direct and indirect part in the process of sound wave formation. In the first case, a mechanical sound is formed when loading or processing raw materials using technological equipment; in the process of brick molding, it is loading the prepared clay mass into the vacuum chamber of the press $[5,6]$. In the second case, the need for processing technological raw materials is the reason for the operation of technological equipment, which is accompanied by intensive release of energy partially converted into sound radiation.

Technological equipment, as an object involved in the sound wave formation, has a significant impact on the characteristics of the acoustic pollution process through its technical characteristics. So the operation of SMK-506 vacuum screw press is characterized by such parameters as type and brand, size of equipment, operation mode, rated capacity [7, 8].

The internal source of sound waves is a part of technological equipment, in the area of which radiation of a noise field occurs in the internal volume of the production room. The internal source of radiation of sound waves in the clay brick workshop of the molding compartment is the SMK-506 screw press engine to the greatest extent.

At the second stage of the air pollution process sound waves are emitted into the air of the internal volume of the room, the objects involved in this stage of the process are presented in figure 3 .

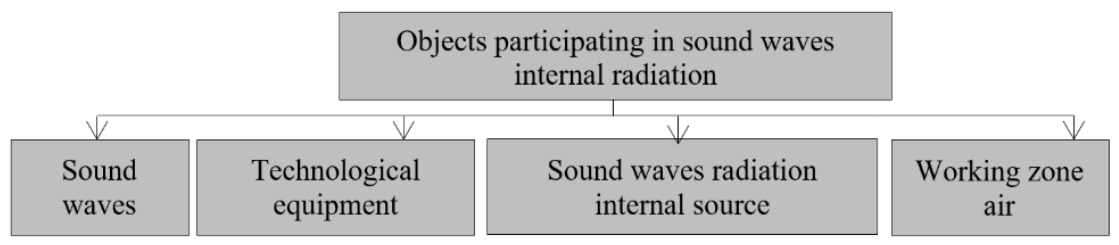

Fig. 3. Objects of the second stage of the air acoustic pollution process.

Sound waves generated in the first stage are considered by us as a physical object participating in the process of internal radiation, taking into account all their physical characteristics, which can be considered as parameters that affect the likelihood of further implementation of the process of acoustic pollution of the air.

The zone of technological equipment directly connected with the air of the working zone in which the radiation of sound waves occurs is an internal radiation source. 
The air of the working area should also be considered as a physical object that takes part in the process of acoustic pollution in the second stage, since the main microclimate parameters directly influence the nature of the sound wave emission [9].

At the third stage, there is an internal propagation of sound waves generated from an internal radiation source into the internal volume of the production room. The nature of the propagation of sound waves is affected by physical characteristics and technical parameters of physical objects shown in figure 4 .

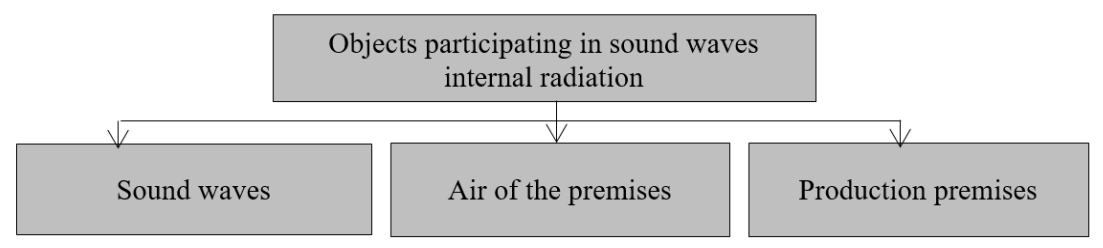

Fig. 4. Objects of the third stage of the air acoustic pollution process.

The main physical object in the third stage of the process, as in the previous one, is sound waves, the nature of propagation of which depends on the microclimate of the air in the production room and its configuration. In case of consideration of brick plants, the production room is a gallery of the conveyor and is characterized by such parameters as geometric characteristics, design features, material of walls, floors, window and door openings [10].

The fourth stage of the process of acoustic pollution of the air environment is the process of external radiation of sound propagating in the internal volume of the production room through an external radiation source into the external air environment.

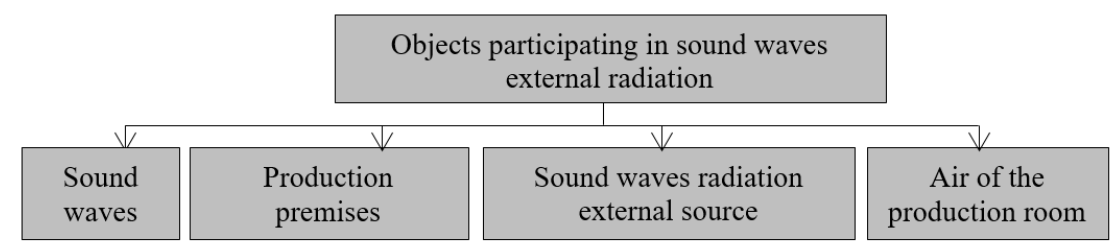

Fig. 5. Objects of the fourth stage of the air acoustic pollution process.

At the fourth stage of acoustic pollution, objects such as an external source of sound waves and industrial premises air are added. The external source of sound wave radiation is the area of the production room, directly connected with the air of the surface layer of the atmosphere and through which the sound wave emits into the external environment. In this case, the external source of radiation of sound waves are window and door openings, characterized by the following parameters: type - point; view - organized, because sound waves are emitted through special openings [11].

At the fifth stage of acoustic pollution, the process of external propagation of sound waves released through an external radiation source in the surface layer of the atmosphere is realized. 


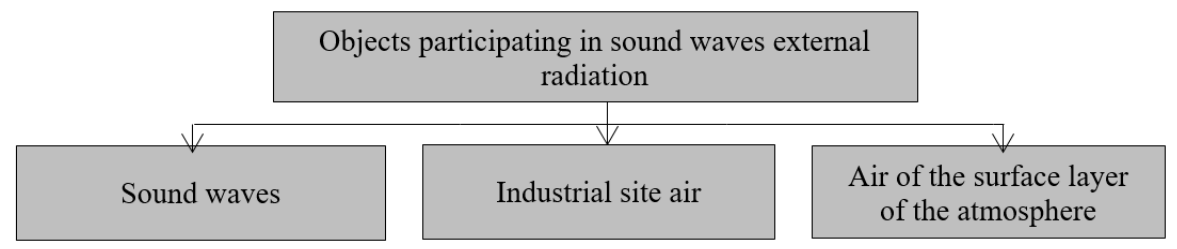

Fig. 6. Objects of the fifth stage of the air acoustic pollution process.

At the same time, such parameters of air as atmospheric pressure, humidity, air velocity and its temperature influence the nature of the propagation of sound waves. The aerodynamic properties of the environment inside the production room and the external environment, features of the terrain, features of industrial and urban buildings also have a significant effect on the spatial distribution of noise [12-14].

An examination of the objects involved at all stages of the process of acoustic pollution of the air allows us to say that the main physical object connecting all other objects is a sound wave. In addition, we can conclude that the process of acoustic pollution of the air, as well as any other physical space, is a multi-stage probabilistic process in which the probability of each subsequent stage depends on the probability of its implementation.

Thus, we can represent the essence of noise pollution of the air environment, taking into account the possibility of implementing sequential, interconnected events. The probability of the acoustic pollution process is presented as the set of probabilities of successively occurring physical processes of the formation of sound waves, sound wave emission in the presence of the conditions for their formation and propagation of sound waves under the condition of the radiation process and is expressed by the formula:

$$
\mathrm{P}_{\text {pol. }}=\mathrm{P}_{\text {for. }} \cdot \mathrm{P}_{\mathrm{emm} .1} \cdot \mathrm{P}_{\text {pro.1. }} \cdot \mathrm{P}_{\mathrm{emm} .2 .} \cdot \mathrm{P}_{\text {pro.2. }}
$$

where $\mathrm{P}_{\text {pol. }}$ is probability of acoustic pollution; $\mathrm{P}_{\text {for. }}$ is probability of sound waves formation; $\mathrm{P}_{\mathrm{emm} .1}$. is probability of the process of emission of sound waves from technological equipment inside the production room during the implementation of the process of their formation; $P_{\text {pro.1. }}$ is probability of the process of propagation of sound waves in the internal volume of a production building subject to the implementation of the radiation process; $\mathrm{P}_{\mathrm{emm} .2 \text {. }}$ is probability of the process of emission of sound waves from external sources of radiation into the air of the industrial site when implementing the process of their propagation in the internal volume of the production room; $\mathrm{P}_{\text {pro.2. }}$ is probability of the process of propagation of sound waves into the surface layer of the atmosphere, provided that the process of radiation from external sources into the air of the industrial site is implemented.

\section{Discussion}

The physical model we constructed for the process of acoustic pollution of an urban environment can be the basis for further studies related to the study and description of the process of reducing acoustic pollution in an urban environment: construction of a physical model of this process, evaluation of various options for soundproofing solutions, and development of a methodology for choosing environmentally-efficient and energy-efficient options for reducing the acoustic pollution of the urban environment. 


\section{References}

1. V.I. Bespalov, N.S. Samarskaya, E.P. Lysova, V.V. Baklakova, N.V. Udina, AIP Conference Proceedings 2188, 060010 (2019). DOI:10.1063/1.5138479

2. F. Aletta, J. Kang, International Journal of Environmental Research and Public Health 16(24), 49-53 (2019). DOI:10.3390/ijerph16244988

3. V. Bespalov, N. Samarskaya, E. Lysova, O. Akay, MATEC Web of Conferences 170 (2018). DOI:10.1051/matecconf $/ 201817003010$

4. V.I. Bespalov, E.V. Kotlyarova, Terra Economicus 4(3), 121-123 (2013)

5. V.I. Bespalov, O.S. Gurova, Engineering Don Vestnik 3(26), 175 (2013)

6. O. Kruzhilko, R. Cherneha, V. Maystrenko, O. Polukarov, V. Kalinchyk, Archives of

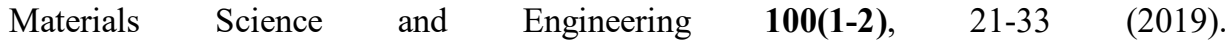
DOI:10.5604/01.3001.0013.5999

7. Z.-Q. Qi, H. Wang, W.-W. Chang, Q.-X. Wang, Journal of Northeastern University 38(11), 1590-1594 (2017). DOI:10.12068/j.issn.1005-3026.2017.11.015

8. K.E. Pushin, I.L. Bukharina, O.P. Druzhakina, Ecology and Industry of Russia 21(5), 16-20 (2017). DOI:10.18412/1816-0395-2017-5-16-20

9. J. Florentin, G. Kouroussis, O. Verlinden, P. Brux, ICSV 2016 - 23rd International Congress on Sound and Vibration: From Ancient to Modern Acoustics, Greece, 123390 (2016)

10. V.P. Gusev, V.I. Ledenev, Izvestiya Vysshikh Uchebnykh Zavedenii, Seriya Teknologiya Tekstil'Noi Promyshlennosti 4, 146-151 (2016)

11. L. P. Singh, A. Bhardwaj, D. K. Kumar, Noise \& Health 14(58), 119-128 (2012)

12. N.V. Bakaeva, D.V. Matyushin, T.M. Novikova, Construction and reconstruction 1(57), 74-83 (2015)

13. A.A. Bykova, N.S. Mihalyuk, A.A. Mishanov, Bulletin of Tula State University. Technical science 2, 303-311 (2014)

14. A.N. Skvorcov, A.P. Savel'ev, S.V. P'yanzov, Bulletin of the Mordovian University 2, 218-227 (2016) 